\title{
Exploration of the Glycosyltransferase BmmGT1 from a Marine- Derived Bacillus Strain as a Potential Enzyme Tool for Compound Glycol-Diversification ${ }^{\mathbb{S}}$
}

\author{
Quanquan Liu ${ }^{1 \dagger}$, Pengfei $\operatorname{Ren}^{1 \dagger}$, Yang $\operatorname{Liu}^{1}$, Wen Qin $^{1}$, Huayue $\mathrm{Li}^{1,2 *}$, and Wenli $\mathrm{Li}^{1,2 *}$ \\ ${ }^{1}$ Key Laboratory of Marine Drugs, Ministry of Education, School of Medicine and Pharmacy, Ocean University of China, Qingdao 266003, \\ P.R. China \\ ${ }^{2}$ Laboratory for Marine Drugs and Bioproducts of Qingdao National Laboratory for Marine Science and Technology, Qingdao 266237, P.R. China
}

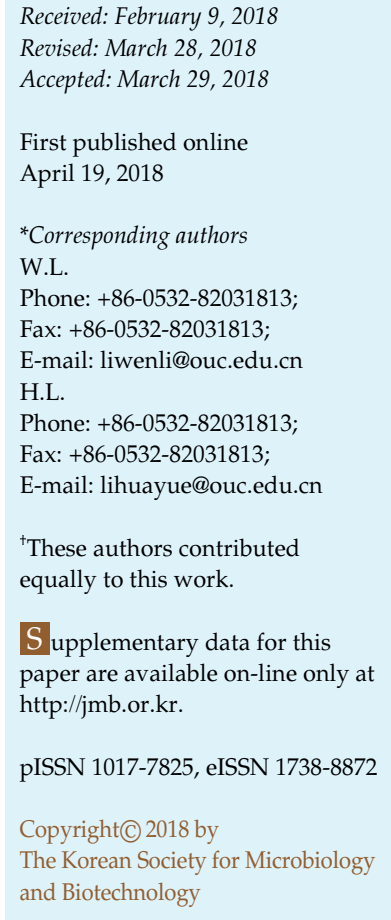

Glycosyltransferases (GTs) from microbes are an emerging and rich source for efficient glycol-transformation of natural/unnatural compounds. Here, we probed the catalytic capability and substrate promiscuity of BmmGT1 from marine-derived Bacillus methylotrophicus B-9987. The regioselectivity of BmmGT1 on macrolactin A (1) was explored by optimization of the reaction conditions, in which a series of $O$-glycosylated macrolactins (1a-1e) were generated, including two new di/tri-O-glucosyl analogs ( $\mathbf{1 b}$ and $\mathbf{1 e})$. Furthermore, BmmGT1 was able to catalyze the glycosylation of the thiol ( $\mathrm{S}-)$ or amine $(\mathrm{N}-)$ sites of phenolic compounds ( 2 and 3), leading to the generation of $N$ - (2a) or S-glycosides $(\mathbf{3 a}$ and $\mathbf{3 b}$ ). The present study demonstrates that BmmGT1 could serve as a potential enzyme tool for $\mathrm{O}_{-}, \mathrm{N}-$, or $\mathrm{S}$-glycosyl structural diversification of compounds for drug discovery.

Keywords: Glycosyltransferase, marine-derived Bacillus, aglycon promiscuity, glycoldiversification, macrolactin

\section{Introduction}

Glycosylation is one of the most important modifications in nature, as it plays an essential role in the biological activity, specificity, and stability, as well as the pharmacokinetics of many natural products [1-3]. Glycosyltransferases (GTs), natural enzyme tools for glycan construction, have attracted growing interest, owing to their high efficiency and regioselectivity in synthetic glycochemistry [4-6]. However, enzyme glycosylation is normally restricted by the verification of suitable GTs for the target compounds [7]. Thus, mining GTs with aglycon promiscuity is an important route to generate diverse, bioactive, glycosylated natural/unnatural products.

In recent years, GTs from microbes have been reported to be a rich source for efficient glycol-transformation of both natural and unnatural compounds [8-11]. In our previous study, we identified and characterized the bmmGT1 gene from marine-derived Bacillus methylotrophicus B-9987 (CGMCC No. 2095), which encodes a protein responsible for the glycosylation of macrolactins (24-membered macrolides) and bacillaenes (polyunsaturated enamines) [12-14]. BmmGT1 exhibited flexible substrate specificity with regard to different aglycons (macrolactin A, malonyl-macrolactin 


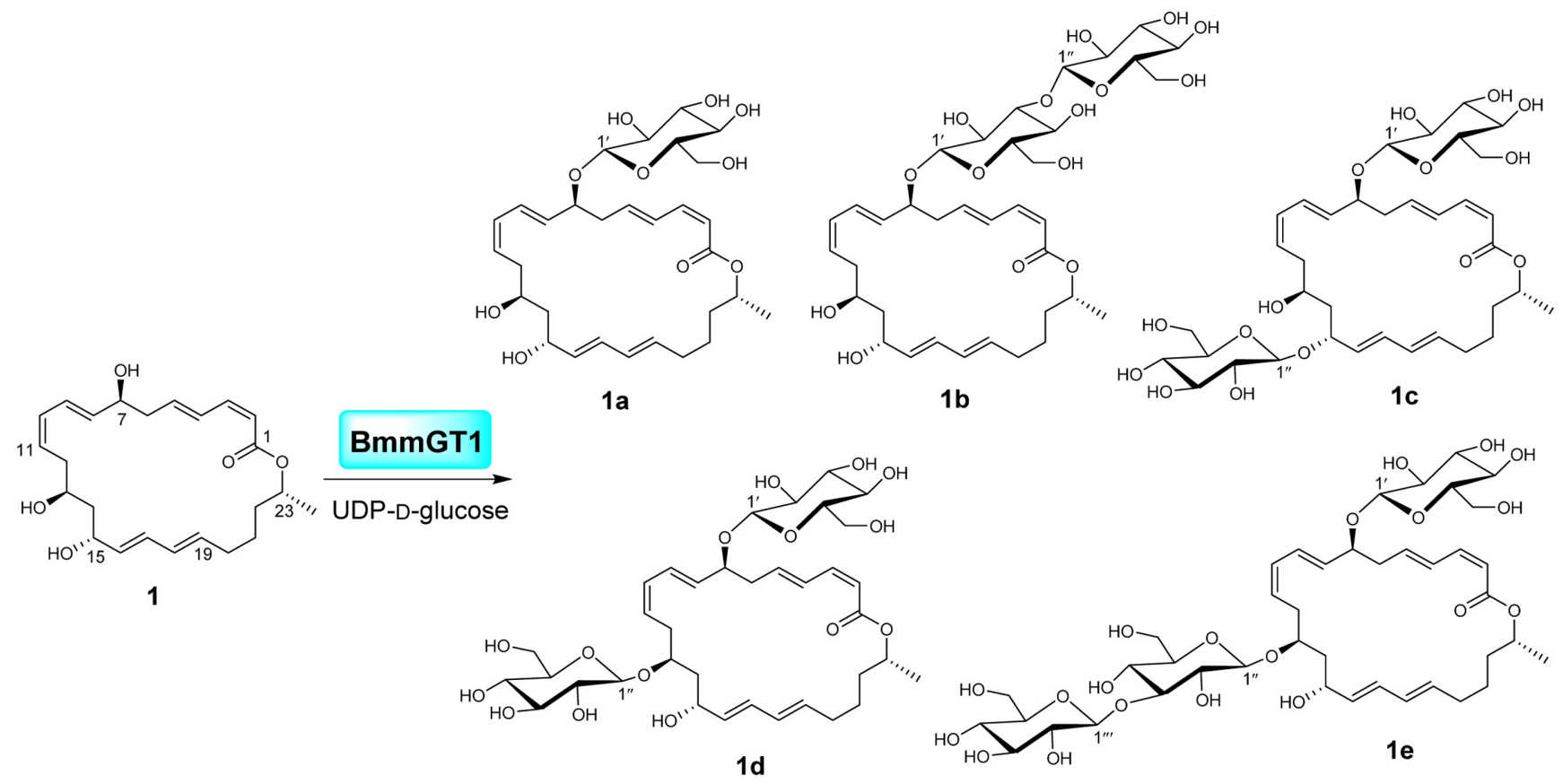

Fig. 1. Structures of macrolactin A (1) and its glycosylated analogs (1a-1e) generated by BmmGT1.

A, and succinyl-macrolactin A) or/and sugar donors (UDP-D-glucose and UDP-D- $N$-acetylglucosamine). In our continuous study to explore the catalytic capability and potential application of BmmGT1 in compound diversification, the reaction conditions and substrate promiscuity of BmmGT1 were further probed herein. A series of $O-$ glycosylated macrolactins (1a-1e) were thus generated (Fig. 1), among which two (1b and 1e) were identified as new compounds. Interestingly, BmmGT1 catalyzed the attachment of sugars to the thiol (S-) or amine (N-) sites of phenolic aglycons ( 2 and 3 ), which generated two known (2a and $\mathbf{3 a}$ ) analogs and one new (3b) one. These results demonstrated that BmmGT1 is not only able to serve as an $O-G T$, but as a $S$-GT and $N$-GT as well.

\section{Materials and Methods}

\section{Experimental}

1D and 2D NMR spectra were recorded on Bruker Avance III 600 spectrometers. Chemical shifts were reported with reference to the respective solvent peaks and residual solvent peaks $\left(\delta_{\mathrm{H}} 2.50\right.$ and $\delta_{\mathrm{C}} 39.5 \mathrm{ppm}$ for DMSO- $\left.d_{6}\right)$. HR-ESIMS data were obtained on a Q-TOF Ultima Global GAA076 LC-MS spectrometer. HPLC was performed on an Agilent 1260 Infinity equipment with diode array detector. The reagent UDP-D-glucose was purchased from Sigma-Aldrich Company, and 3,4-dichloroaniline (2) and 3,4dichlorobenzenethiophenol (3) were purchased from Shanghai Energy Chemical Company (China).

\section{Bacterial Strains and Culture Conditions}

Escherichia coli BL21 (DE3) was used as a host for protein expression. E.coli strains and Bacillus strains were routinely cultured in Luria-Bertani (LB) liquid medium at $37^{\circ} \mathrm{C}$ and $200 \mathrm{rpm}$, or on LB agar plates at $37^{\circ} \mathrm{C}$. When appropriate, kanamycin (s100 $\mu \mathrm{g} / \mathrm{ml}$ for E. coli) or erythromycin $(5 \mu \mathrm{g} / \mathrm{ml}$ for Bacillus) was added to the medium.

\section{Heterologous Expression and Purification of BmmGT1}

The pWLI206 plasmid harboring the bmmGT1 gene was constructed previously [13]. Expression of the recombinant protein was induced at an $\mathrm{OD}_{600}$ of approximately 0.6 by addition of isopropyl- $\beta$-D-thiogalactopyranoside $(0.4 \mathrm{mM}$ final concentration), and cultivation was continued for an additional $16 \mathrm{~h}$ at $16^{\circ} \mathrm{C}$. Cells were harvested by centrifugation at 10,000 $\times g$, washed twice, and resuspended in Tris- $\mathrm{HCl}$ buffer $(50 \mathrm{mM}, \mathrm{pH} 7.5)$. The resuspended cells were lysed by sonication in an ice-water bath with the ultrasonic processor VCX750 (Sonics \& Materials Inc., USA), and centrifuged at $11,000 \times g$ for $30 \mathrm{~min}$ at $4^{\circ} \mathrm{C}$. The supernatant was applied to a HisTrap HP column (1 ml; GE Healthcare, USA) and the $\mathrm{N}$-(His) ${ }_{6}$-tagged BmmGT1 protein was eluted with a linear gradient of imidazole $(10-500 \mathrm{mM})$ in the binding buffer using a AKTA Purifier system. The purified proteins was desalted using the Ultrafree ${ }^{\circledR}-4$ Centrifugal Filter Unit (Millipore, Bedford, USA), and stored in Tris- $\mathrm{HCl}(50 \mathrm{mM}, \mathrm{pH} 8.0)$ buffer containing glycerol $(10 \%)$ at $-80^{\circ} \mathrm{C}$ until use.

\section{In Vitro Assays of BmmGT1}

The substrate macrolactin A (1) was obtained from large-scale 
fermentation $(20 \mathrm{~L})$ of the $\triangle b m m G T 1$ mutant strain as previously described [13]. The concentration of BmmGT1 was determined by the Bradford method with bovine serum albumin as the standard. To explore the catalytic capability of BmmGT1 at diverse reaction conditions, reaction mixtures $(50 \mu \mathrm{l})$ consisting of compound 1 (0.2-1.0 mM), UDP-D-glucose (1.0-8.0 mM), BmmGT1 (0.2-12 $\mu \mathrm{M})$, and $\mathrm{MgCl}_{2}(10 \mu \mathrm{M})$ in Tris- $\mathrm{HCl}(50 \mathrm{mM}, \mathrm{pH}$ 8.9) were prepared, which were incubated at $30^{\circ} \mathrm{C}$ for diverse reaction times $(0.5-12 \mathrm{~h})$ and quenched by addition of acetonitrile $(50 \mu \mathrm{l})$. Then, the denatured protein was removed by centrifugation, and the supernatants were monitored by HPLC analysis with a YMC pack ODS-AQ column ( $5 \mathrm{~mm}, 150 \times 4.6 \mathrm{~mm}$; YMC Co., Japan) with UV detection at $260 \mathrm{~nm}$. The in vitro assays of BmmGT1 with compounds 2 and 3 were performed in a reaction $(50 \mu \mathrm{l})$ containing compound 2 or $3(100 \mu \mathrm{M})$, UDP-D-glucose $(1 \mathrm{mM})$, BmmGT1 $(10 \mu \mathrm{M}), \mathrm{MgCl}_{2}(10 \mu \mathrm{M})$, and Tris- $\mathrm{HCl}(50 \mathrm{mM}, \mathrm{pH}$ 8.9). The reaction mixtures were incubated at $30^{\circ} \mathrm{C}$ for $2 \mathrm{~h}$ and quenched by addition of acetonitrile $(50 \mu \mathrm{l})$. The supernatants were monitored by HPLC analysis with a YMC pack ODS-AQ C18 column $(150 \mathrm{~mm}, 150 \times 4.6 \mathrm{~mm} ; 5 \mu \mathrm{m})$ with UV detection at $254 \mathrm{~nm}$.

\section{Isolation of Glycosylated Macrolactin Analogs}

To isolate the compounds $\mathbf{1} \mathbf{b}-\mathbf{1 e}$, large-scale reactions containing $8 \mu \mathrm{M}$ of BmmGT1, $0.2 \mathrm{mM}$ of 1 , and $4 \mathrm{mM}$ of UDP-D-glucose were performed, which were then purified on a semi-preparative HPLC YMC-Pack ODS-A C18 column $(250 \mathrm{~mm} \times 10 \mathrm{~mm}$, i.d. $5 \mu \mathrm{m})$ with UV detection at $260 \mathrm{~nm}$ to afford $1 \mathrm{~b}(0.8 \mathrm{mg}), \mathbf{1 c}(1.1 \mathrm{mg}), \mathbf{1 d}$ $(1.1 \mathrm{mg})$, and $1 \mathrm{e}(1.3 \mathrm{mg})$, respectively.

\section{Results and Discussion}

The glycosyltransferase BmmGT1 from marine-derived B. methylotrophicus B-9987 was prepared by the method we described previously [13]. To explore the catalytic capability of BmmGT1, the enzymatic activities under diverse reaction conditions, including the reaction time and the working concentrations of the enzyme and substrate (1), were tested, followed by HPLC analysis. As shown in Fig. 2A, as the time was increased from $30 \mathrm{~min}$ to $1 \mathrm{~h}$, the conversion rates increased from $48 \%$ to $53 \%$ and reached $100 \%$ at $2 \mathrm{~h}$; the production of macrolactin B (1a) started to decrease at $4 \mathrm{~h}$, and simultaneously, $\mathbf{1 c}, \mathbf{1 d}$, and $\mathbf{1 b}$ appeared successively. However, the substrate macrolactin A (1) reappeared at $12 \mathrm{~h}$, indicating that the reverse reaction happened after a long incubation time. On the other hand, as the enzyme concentration was increased from 0.2 to $2 \mu \mathrm{M}, 1 \mathrm{c}, 1 \mathbf{d}$, and $\mathbf{1 b}$ appeared successively, in addition to $\mathbf{1 a}$, and another glycosylated compound, 1e, appeared at a concentration of $4 \mu \mathrm{M}$ and higher (Fig. 2B). Under the conditions of $1 \mathrm{mM}$ UDP-D-glucose and $8 \mu \mathrm{M}$ BmmGT1, $0.2 \mathrm{mM}$ of 1 was totally transformed into $1 \mathrm{a}$, whereas $0.4 \mathrm{mM}$ of 1 and above gave a $62 \%$ conversion rate (Fig. $2 \mathrm{C}$ ). Thus, $0.2 \mathrm{mM}$ of 1 was adopted to probe the concentration of UDP-D-glucose, which revealed that when the concentration of UDP-Dglucose reached $4 \mathrm{mM}$, the majority of 1 was transformed into compounds with multiple sugar moieties (Fig. 2D).

To determine the structure of the newly produced glycosylated macrolactins, a large-scale reaction was subsequently performed using the optimal conditions established above: $0.2 \mathrm{mM}$ of $1,8 \mu \mathrm{M}$ of BmmGT1, and $4 \mathrm{mM}$ of UDP-D-glucose, incubated at $30^{\circ} \mathrm{C}$ for $2 \mathrm{~h}$, to obtain 1b-1e. According to the HR-ESIMS data, the molecular formulae of $\mathbf{1 b}-\mathbf{1 d}$ were established as $\mathrm{C}_{36} \mathrm{H}_{54} \mathrm{O}_{15}$ (at $\mathrm{m} / \mathrm{z}$ $749.3393[\mathrm{M}+\mathrm{Na}]^{+}, 744.3853\left[\mathrm{M}+\mathrm{NH}_{4}\right]^{+}$, and $744.3856[\mathrm{M}$ $\left.+\mathrm{NH}_{4}\right]^{+}$, respectively (calcd. 726.3463)), indicating the attachment of two glucosyl substituents onto 1; 1e was determined to be $\mathrm{C}_{42} \mathrm{H}_{64} \mathrm{O}_{20}\left([\mathrm{M}+\mathrm{Na}]^{+}\right.$at $\mathrm{m} / \mathrm{z} 911.3893$ (calcd. 888.3991)), indicative of a triglucosyl substitution (Fig. S6). The structures of $\mathbf{1 b}-\mathbf{1 e}$ were determined by $1 \mathrm{D}\left({ }^{1} \mathrm{H}\right.$ and ${ }^{13} \mathrm{C}$ ) and 2D (COSY, HSQC, HMBC, and NOESY) NMR data assignment. The macrolactin ring of each compound was established by a combination of corresponding COSY, HSQC, and HMBC correlations. In the HMBC spectra of 1b-1e (Figs. S5, S10-S12), we observed the correlations from $\mathrm{H}-7$ to the anomeric carbon $\mathrm{C}-1^{\prime}$ for each compound, indicating a preference for 7-OH catalyzation of BmmGT1 towards macrolactin A (1). According to the HSQC spectrum of $\mathbf{1 b}$, the NMR chemical shifts of $\mathrm{H} / \mathrm{C}-13$ and $\mathrm{H} / \mathrm{C}-15$ were almost identical to those of 1 [15], revealing that the glucosyl unit was not located at these two positions. In the HMBC spectrum of $\mathbf{1 b}$, we observed a correlation from $\mathrm{H}-3^{\prime}$ $\left(\delta_{\mathrm{H}} 3.35\right)$ to the anomeric carbon C- $3^{\prime \prime}\left(\delta_{\mathrm{C}} 103.7\right)$, suggesting that the second glucose was attached to the 7-O-glucosyl unit to form a $1 \rightarrow 3$ diglucosyl moiety. Moreover, both of the anomeric protons $\mathrm{H}-1^{\prime}\left(\delta_{\mathrm{H}} 4.24, \mathrm{~d}, J=7.8 \mathrm{~Hz}\right)$ and $\mathrm{H}-1^{\prime \prime}$ $\left(\delta_{\mathrm{H}} 4.31, \mathrm{~d}, J=7.8 \mathrm{~Hz}\right)$ in $\mathbf{1 b}$ displayed the typical $\beta$-linkage NMR values of glucoses. Thus, $\mathbf{1 b}$ was identified as a new $7-O-[\beta$-D-glucosyl- $(1 \rightarrow 3)-\beta$-D-glucosyl]-macrolactin A. The ${ }^{1} \mathrm{H}$ and ${ }^{13} \mathrm{C}$ NMR chemical shift values of $1 \mathrm{c}$ and $1 \mathrm{~d}$ revealed that they were 7,15-di-O- $\beta$-D-glucosyl and 7,13-di$O-\beta$-D-glucosyl macrolactin A analogs, respectively, which have been reported in our previous publication [14]. Except for the 7-O-glucosyl unit, 1e has two additional glucosyl units. In the ${ }^{1} \mathrm{H}$ NMR spectrum of $1 \mathbf{e}$, the signals for the three glucosyl moieties overlapped severely; thus, the exact chemical shift values for each glucosyl unit in 1e were determined with the help of signal integration in the HSQC spectrum (Fig. 3A). The HMBC correlations of H-13/C-1', $\mathrm{H}-1^{\prime \prime} / \mathrm{C}-3^{\prime \prime}$, and $\mathrm{H}-3^{\prime \prime} / \mathrm{C}-1^{\prime \prime \prime}$ in $1 \mathrm{e}$ revealed that a $1 \rightarrow 3-$ linked diglucosyl moiety was connected to $13-\mathrm{OH}$ (Fig. 3B). 
A

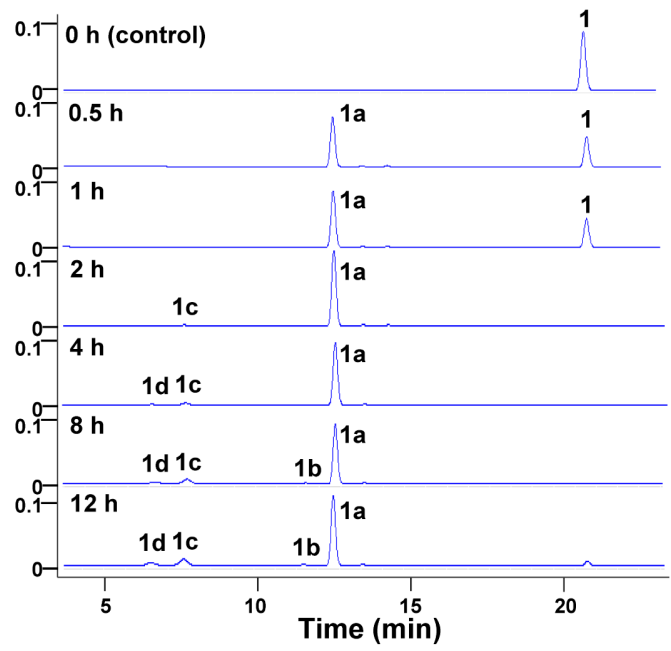

C

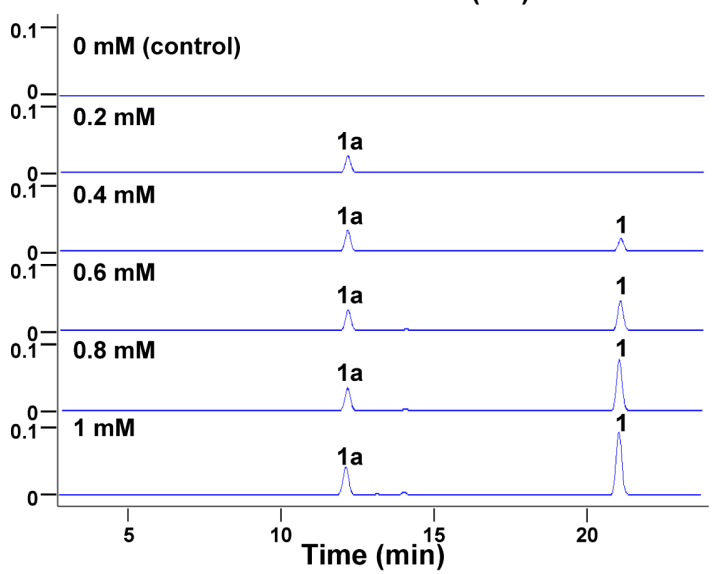

B

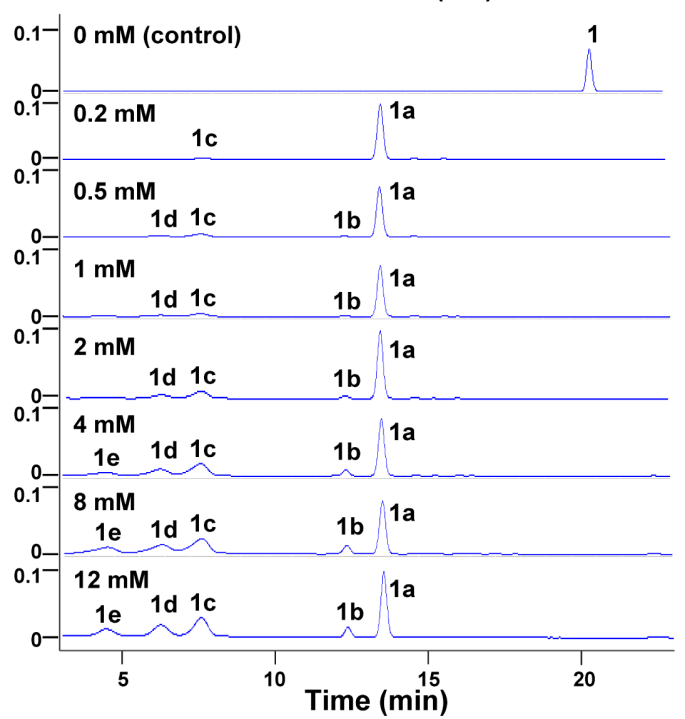

D

UV at $260 \mathrm{~nm}(\mathrm{AU})$

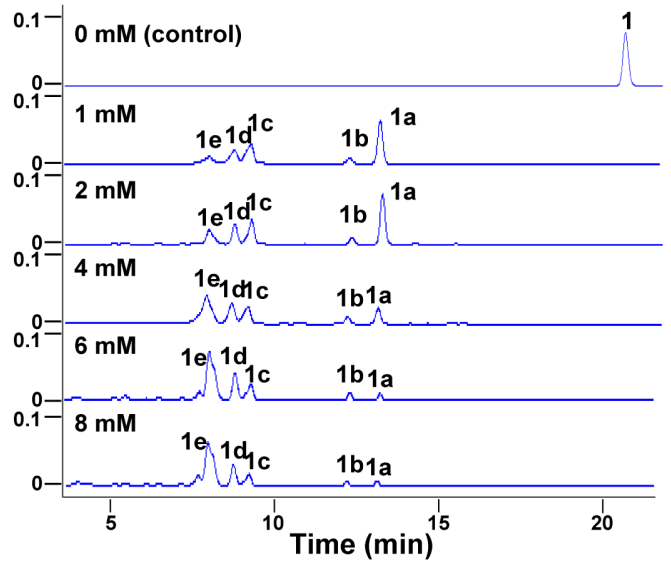

Fig. 2. Catalytic capability of BmmGT1 under diverse reaction conditions, including reaction time (0-12 h) (A), concentrations of BmmGT1 (0-12 mM) (B), concentrations of macrolactin A (1) (0-1 mM) (C), and concentrations of UDP-D-glucose (0-8 mM) (D).

All three of the anomeric protons of $\mathrm{H}^{-1} \mathrm{1}^{\prime}\left(\delta_{\mathrm{H}} 4.42, \mathrm{~d}, J=7.8\right.$ $\mathrm{Hz}), \mathrm{H}-1^{\prime \prime}\left(\delta_{\mathrm{H}} 4.39, \mathrm{~d}, J=7.8 \mathrm{~Hz}\right)$, and $\mathrm{H}-1^{\prime \prime \prime}\left(\delta_{\mathrm{H}} 4.31, \mathrm{~d}\right.$, $J=7.8 \mathrm{~Hz}$ ) in 1e demonstrated a $\beta$-linkage between each glucose and aglycon. Thus, 1e was identified as a new analog, $\quad 7-O-\beta$-D-glucosyl-13-O-[ $\beta$-D-glucosyl- $(1 \rightarrow 3)-\beta-\mathrm{D}-$ glucosyl]-macrolactin $\mathrm{A}$. The ${ }^{1} \mathrm{H}$ and ${ }^{13} \mathrm{C}$ NMR chemical shift values of $\mathbf{1 b}$ and $\mathbf{1 e}$ are summarized in Table 1.

To further investigate the aglycon promiscuity of BmmGT1, we probed the $N$ - and S-glycosylation activities of BmmGT1 using 3,4-dichloroaniline (2) and 3,4dichlorobenzenethiophenol (3) as acceptors [16]. As shown in Fig. 4, BmmGT1 was able to recognize both compounds to generate $N$-glucosyl (2a) and S-glucosyl (3a and $\mathbf{3 b}$ ) analogs from 2 and 3 , respectively. On the basis of the HRESIMS data, the molecular formulae of $2 \mathrm{a}([\mathrm{M}+\mathrm{HCOOH}-$ $\mathrm{H}^{-}$at $m / z$ 368.0291 (calcd. 323.0327)) (Fig. S13) and 3a ([M + $\mathrm{HCOOH} \mathrm{-} \mathrm{H]}]^{-}$at $m / z$ 384.9914, calcd. 339.9939) (Fig. S14) were established as $\mathrm{C}_{12} \mathrm{H}_{15} \mathrm{Cl}_{2} \mathrm{NO}_{5}$ and $\mathrm{C}_{12} \mathrm{H}_{14} \mathrm{Cl}_{2} \mathrm{O}_{5} \mathrm{~S}$, respectively, indicative of a monoglucosyl substitution for each compound. The HR-ESIMS data of $\mathbf{3 b}$ showed a molecular ion peak at $m / z 547.0449[\mathrm{M}+\mathrm{HCOOH}-\mathrm{H}]^{-}$, establishing its molecular formula as $\mathrm{C}_{18} \mathrm{H}_{24} \mathrm{Cl}_{2} \mathrm{O}_{10} \mathrm{~S}$ (calcd. 502.0467) (Fig. S15). According to the results of a SciFinder search, no diglucosylated analogs of $\mathbf{3}$ have been reported. Thus, $\mathbf{3 b}$ is speculated to be a new S-glucosyl analog, for which the linkage pattern of the two glucosyl units needs further 
A

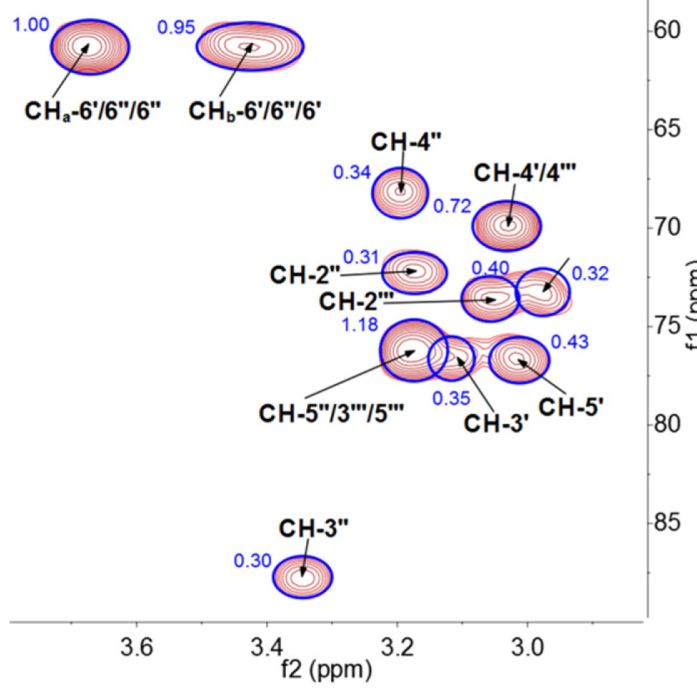

B

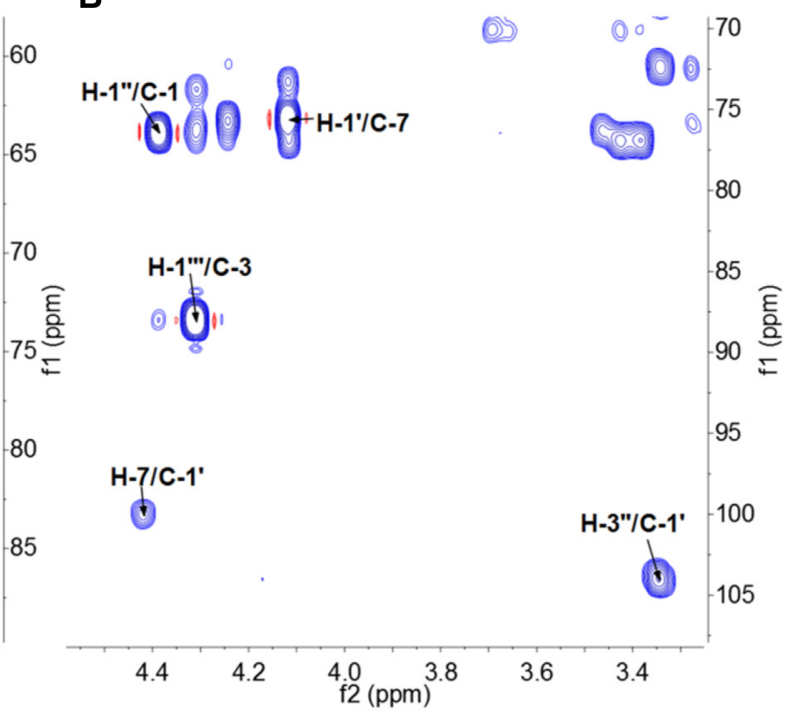

Fig. 3. Expanded HSQC (A) and HMBC (B) spectra of 1e.

(A) The ellipses and numbers in blue represent the integration shape and corresponding values, respectively. The protonated carbons for each glucosyl unit are labeled. (B) Key HMBC correlations determining the location of each glucosyl unit are labeled.

\section{determination.}

Previously, we demonstrated that BmmGT1 prefers the $7-\mathrm{OH}$ of macrolactins, and only acts on $13-\mathrm{OH}$ or $15-\mathrm{OH}$, when 7-OH is not available [14]. Interestingly, by changing the reaction conditions, several glycosylated macrolactins with different sugar patterns were obtained. The timing of the appearances of $\mathbf{1 a}, \mathbf{1 c}$, and $\mathbf{1 d}$ clearly illustrates that the preference order for glycosyl transfer by BmmGT1 should be $7-\mathrm{OH}>13-\mathrm{OH}>15-\mathrm{OH}$. Although we obtained the 7,13and 7,15-di-O-glycosylated analogs $1 \mathrm{c}$ and $1 \mathbf{d}$, we did not obtain a 7,13,15-tri-O-glucosylated analog with any of the reaction conditions (Fig. 2), whose generation might be inhibited by steric hindrance. The production of di/tri-Oglycosylated macrolactin analogs (1b and $\mathbf{1 e}$ ), containing a glu-glu unit, indicated the potent capability of BmmGT1 for sugar-chain generation. Moreover, simple aromatics with the nucleophilic groups of $-\mathrm{NH}_{2}$ and $-\mathrm{SH}$ were used for the enzymatic assays. Interestingly, BmmGT1 also exhibited $\mathrm{N}$ - and S-glycosylation activities toward 3,4dichloroaniline (2) and 3,4-dichlorobenzenethiophenol (3),

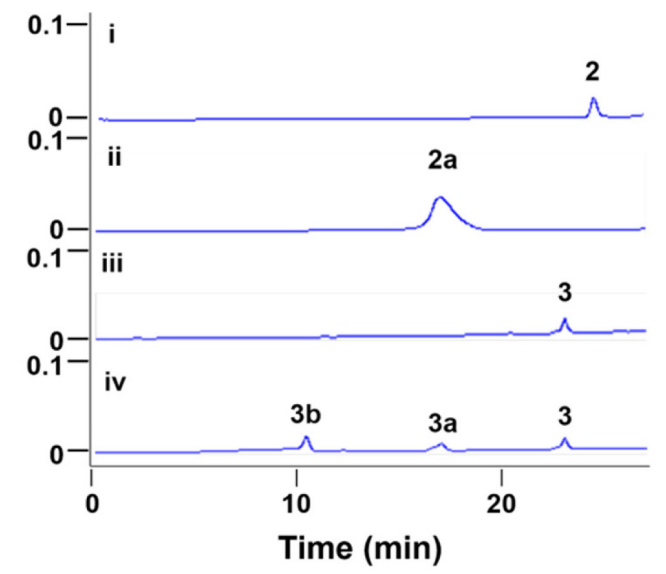<smiles>Nc1ccc(Cl)c(Cl)c1</smiles>

2<smiles>Sc1ccc(Cl)c(Cl)c1</smiles>

3

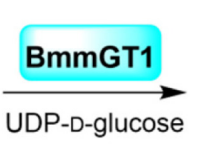<smiles>[R]Nc1ccc(Cl)c(Cl)c1</smiles>

2a: $R=$ D-glucose

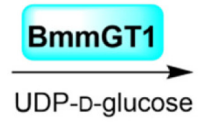<smiles>[R]Sc1ccc(Cl)c(Cl)c1</smiles>

3a: $R=D$-glucose

3b: $R=$ di-D-glucose

Fig. 4. BmmGT1-catalyzed reactions using 3,4-dichloroaniline (2) and 3,4-dichlorobenzenethiophenol (3) as aglycons. (i) 2 + UDP-D-glucose; (ii) 2 + UDP-D-glucose + BmmGT1; (iii) 3 + UDP-D-glucose; (iv) 3 + UDP-D-glucose + BmmGT1. 
Table $1 .{ }^{1} \mathrm{H}$ and ${ }^{13} \mathrm{C}$ NMR chemical shifts of $\mathbf{1 b}$ and $\mathbf{1 e}$ in DMSO- $d_{6}$.

\begin{tabular}{|c|c|c|c|c|}
\hline \multirow[t]{2}{*}{ Position } & \multicolumn{2}{|l|}{$1 \mathrm{~b}$} & \multicolumn{2}{|l|}{$1 e$} \\
\hline & $\delta_{\mathrm{H}}(J$ in $\mathrm{Hz})$ & $\delta_{\mathrm{C}}$ & $\delta_{\mathrm{H}}(J$ in $\mathrm{Hz})$ & $\delta_{\mathrm{C}}$ \\
\hline 1 & & 165.4 & & 165.4 \\
\hline 2 & $5.56(1 \mathrm{H}, \mathrm{m})$ & 116.4 & $5.57(1 \mathrm{H}, \mathrm{m})$ & 116.4 \\
\hline 3 & $6.66(1 \mathrm{H}, \mathrm{m})$ & 143.5 & $6.67(1 \mathrm{H}, \mathrm{m})$ & 143.5 \\
\hline 4 & $7.08(1 \mathrm{H}, \mathrm{dd}, 15.0,12.0)$ & 127.7 & $7.08(1 \mathrm{H}, \mathrm{dd}, 15.0,12.0)$ & 127.7 \\
\hline 5 & $6.22(1 \mathrm{H}, \mathrm{m})$ & 141.1 & $6.23(1 \mathrm{H}, \mathrm{m})$ & 141.2 \\
\hline \multirow[t]{2}{*}{6} & $2.49(1 \mathrm{H}, \mathrm{m})$ & 39.9 & $2.49(1 \mathrm{H}, \mathrm{m})$ & 39.7 \\
\hline & $2.37(1 \mathrm{H}, \mathrm{m})$ & & $2.37(1 \mathrm{H}, \mathrm{m})$ & \\
\hline 7 & $4.42(1 \mathrm{H}, \mathrm{m})$ & 75.5 & $4.42(1 \mathrm{H}, \mathrm{m})$ & 75.4 \\
\hline 8 & $5.56(1 \mathrm{H}, \mathrm{m})$ & 132.9 & $5.56(1 \mathrm{H}, \mathrm{m})$ & 132.9 \\
\hline 9 & $6.65(1 \mathrm{H}, \mathrm{m})$ & 126.8 & $6.65(1 \mathrm{H}, \mathrm{m})$ & 127.1 \\
\hline 10 & $6.05(1 \mathrm{H}, \mathrm{m})$ & 129.3 & $6.08(1 \mathrm{H}, \mathrm{m})$ & 129.6 \\
\hline 11 & $5.51(1 \mathrm{H}, \mathrm{m})$ & 128.5 & $5.51(1 \mathrm{H}, \mathrm{m})$ & 128.3 \\
\hline \multirow[t]{2}{*}{12} & $2.35(1 \mathrm{H}, \mathrm{m})$ & 35.4 & $2.47(1 \mathrm{H}, \mathrm{m})$ & 35.2 \\
\hline & $2.24(1 \mathrm{H}, \mathrm{m})$ & & $2.31(1 \mathrm{H}, \mathrm{m})$ & \\
\hline 13 & $3.75(1 \mathrm{H}, \mathrm{m})$ & 66.1 & $3.90(1 \mathrm{H}, \mathrm{m})$ & 76.2 \\
\hline \multirow[t]{2}{*}{14} & $1.32(2 \mathrm{H}, \mathrm{m})$ & 42.8 & $1.49(1 \mathrm{H}, \mathrm{m})$ & 40.9 \\
\hline & & & $1.30(1 \mathrm{H}, \mathrm{m})$ & \\
\hline 15 & $4.15(1 \mathrm{H}, \mathrm{m})$ & 66.6 & $4.30(1 \mathrm{H}, \mathrm{m})$ & 65.7 \\
\hline 16 & $5.52(1 \mathrm{H}, \mathrm{m})$ & 136.2 & $5.54(1 \mathrm{H}, \mathrm{m})$ & 136.0 \\
\hline 17 & $6.03(1 \mathrm{H}, \mathrm{m})$ & 127.6 & $6.03(1 \mathrm{H}, \mathrm{m})$ & 127.6 \\
\hline 18 & $5.99(1 \mathrm{H}, \mathrm{m})$ & 130.0 & $6.00(1 \mathrm{H}, \mathrm{m})$ & 130.0 \\
\hline 19 & $5.56(1 \mathrm{H}, \mathrm{m})$ & 132.4 & $5.56(1 \mathrm{H}, \mathrm{m})$ & 132.6 \\
\hline 20 & $2.08(2 \mathrm{H}, \mathrm{m})$ & 30.9 & $2.08(2 \mathrm{H}, \mathrm{m})$ & 30.9 \\
\hline 21 & $1.40(2 \mathrm{H}, \mathrm{m})$ & 23.6 & $1.39(2 \mathrm{H}, \mathrm{m})$ & 23.6 \\
\hline \multirow[t]{2}{*}{22} & $1.52(2 \mathrm{H}, \mathrm{m})$ & 33.9 & $1.53(1 \mathrm{H}, \mathrm{m})$ & 33.9 \\
\hline & & & $1.48(1 \mathrm{H}, \mathrm{m})$ & \\
\hline 23 & $4.94(1 \mathrm{H}, \mathrm{m})$ & 69.6 & $4.95(1 \mathrm{H}, \mathrm{m})$ & 69.6 \\
\hline 24 & $1.19(3 \mathrm{H}, \mathrm{d}, 6.0)$ & 19.3 & $1.19(3 \mathrm{H}, \mathrm{d}, 6.0)$ & 19.3 \\
\hline $1^{\prime}$ & $4.24(1 \mathrm{H}, \mathrm{d}, 8.4)$ & 99.2 & $4.12(1 \mathrm{H}, \mathrm{d}, 8.4)$ & 99.6 \\
\hline $2^{\prime}$ & $3.21(1 \mathrm{H}, \mathrm{m})$ & 71.9 & $2.99(1 \mathrm{H}, \mathrm{m})$ & 73.3 \\
\hline $3^{\prime}$ & $3.35(1 \mathrm{H}, \mathrm{m})$ & 87.7 & $3.11(1 \mathrm{H}, \mathrm{m})$ & 76.5 \\
\hline $4^{\prime}$ & $3.19(1 \mathrm{H}, \mathrm{m})$ & 68.2 & $3.03(1 \mathrm{H}, \mathrm{m})$ & 69.9 \\
\hline $5^{\prime}$ & $3.18(1 \mathrm{H}, \mathrm{m})$ & 76.4 & $3.01(1 \mathrm{H}, \mathrm{m})$ & 76.7 \\
\hline \multirow[t]{2}{*}{$6^{\prime}$} & $3.68(1 \mathrm{H}, \mathrm{m})$ & 60.7 & $3.67(1 \mathrm{H}, \mathrm{m})$ & 60.8 \\
\hline & $3.43(1 \mathrm{H}, \mathrm{m})$ & & $3.43(1 \mathrm{H}, \mathrm{m})$ & \\
\hline $1^{\prime \prime}$ & $4.31(1 \mathrm{H}, \mathrm{d}, 8.4)$ & 103.7 & $4.39(1 \mathrm{H}, \mathrm{d}, 8.4)$ & 102.9 \\
\hline $2^{\prime \prime}$ & $3.05(1 \mathrm{H}, \mathrm{m})$ & 73.5 & $3.17(1 \mathrm{H}, \mathrm{m})$ & 72.2 \\
\hline $3^{\prime \prime}$ & $3.10(1 \mathrm{H}, \mathrm{m})$ & 76.2 & $3.34(1 \mathrm{H}, \mathrm{m})$ & 87.8 \\
\hline $4^{\prime \prime}$ & $3.03(1 \mathrm{H}, \mathrm{m})$ & 69.8 & $3.20(1 \mathrm{H}, \mathrm{m})$ & 68.2 \\
\hline $5^{\prime \prime}$ & $3.18(1 \mathrm{H}, \mathrm{m})$ & 76.4 & $3.18(1 \mathrm{H}, \mathrm{m})$ & 76.2 \\
\hline \multirow[t]{2}{*}{$6^{\prime \prime}$} & $3.68(1 \mathrm{H}, \mathrm{m})$ & 60.7 & $3.67(1 \mathrm{H}, \mathrm{m})$ & 60.8 \\
\hline & $3.43(1 \mathrm{H}, \mathrm{m})$ & & $3.43(1 \mathrm{H}, \mathrm{m})$ & \\
\hline $1^{\prime \prime \prime}$ & & & $4.31(1 \mathrm{H}, \mathrm{d}, 8.4)$ & 103.8 \\
\hline $2^{\prime \prime \prime}$ & & & $3.05(1 \mathrm{H}, \mathrm{m})$ & 73.7 \\
\hline $3^{\prime \prime \prime}$ & & & $3.18(1 \mathrm{H}, \mathrm{m})$ & 76.2 \\
\hline $4^{\prime \prime \prime}$ & & & $3.03(1 \mathrm{H}, \mathrm{m})$ & 69.9 \\
\hline $5^{\prime \prime \prime}$ & & & $3.18(1 \mathrm{H}, \mathrm{m})$ & 76.2 \\
\hline \multirow[t]{2}{*}{$6^{\prime \prime \prime}$} & & & $3.67(1 \mathrm{H}, \mathrm{m})$ & 60.8 \\
\hline & & & $3.43(1 \mathrm{H}, \mathrm{m})$ & \\
\hline
\end{tabular}


indicating that BmmGT1 has broad aglycon promiscuity.

In summary, we have probed the aglycon promiscuity of the glycosyltransferase BmmGT1 from marine-derived B. methylotrophicus B-9987. The regioselectivity of BmmGT1 toward macrolactin A (1) was explored by optimization of the reaction conditions, which generated a series of $O$-glycosylated macrolactin analogs, including two new $\mathrm{di} /$ tri-O-glucosyl analogs (1b and $\mathbf{1 e}$ ). In the investigation of the catalyzation capability of BmmGT1 toward unnatural phenolic compounds (2 and 3), the enzyme recognized both aglycons and generated $N$ - (2a) or S-glycosides (3a and $\mathbf{3 b}$ ), among which $\mathbf{3 b}$ was speculated to be a new di-Sglucosyl analog. The present study demonstrates that BmmGT1 could be used as a potential enzyme tool for the structural diversification of $\mathrm{O}-, \mathrm{N-}$, or S-glycosylated natural/ unnatural products.

\section{Acknowledgments}

This work was supported by grants from the NSFCShandong Joint Fund for Marine Science Research Centers (U1706206 \& U1606403), the National Natural Science Foundation of China (21502180 \& 41506157), and the Scientific and Technological Innovation Project Financially Supported by Qingdao National Laboratory for Marine Science and Technology (2015ASKJ02).

\section{Conflict of Interest}

The authors have no financial conflicts of interest to declare.

\section{References}

1. Song MC, Kim E, Ban YH, Yoo YJ, Kim EJ, Park SR, et al. 2013. Achievements and impacts of glycosylation reactions involved in natural product biosynthesis in prokaryotes. Appl. Microbiol. Biotechnol. 97: 5691-5704.

2. Weymouth-Wilson AC. 1997. The role of carbohydrates in biologically active natural products. Nat. Prod. Rep. 14: 99-110.

3. Vajaria BN, Patel PS. 2017. Glycosylation: a hallmark of cancer? Glycoconj. J. 34: 147-156.
4. Thibodeaux CJ, Melancon CE, Liu HW. 2007. Unusual sugar biosynthesis and natural product glycodiversification. Nature 446: 1008-1016.

5. Gantt RW, Peltier-Pain P, Thorson JS. 2011. Enzymatic methods for glyco (diversification/randomization) of drugs and small molecules. Nat. Prod. Rep. 28: 1811-1853.

6. Zhan YT, Su HY, An W. 2016. Glycosyltransferases and non-alcoholic fatty liver disease. World J. Gastroenterol. 22: 2483-2493.

7. Thibodeaux CJ, Melancon CE, Liu HW. 2008. Naturalproduct sugar biosynthesis and enzymatic glycodiversification. Angew. Chem. Int. Ed. Engl. 47: 9814-9859.

8. Gantt RW, Goff RD, Williams GJ, Thorson JS. 2008. Probing the aglycon promiscuity of an engineered glycosyltransferase. Angew. Chem. Int. Ed. Engl. 47: 8889-8892.

9. Chen R, Zhang Q, Tan B, Zheng L, Li H, Zhu Y, Zhang C. 2017. Genome mining and activation of a silent PKS/NRPS gene cluster direct the production of totopotensamides. Org. Lett. 19: 5697-5700.

10. Salem SM, Weidenbach S, Rohr J. 2017. Two cooperative glycosyltransferases are responsible for the sugar diversity of saquayamycins isolated from Streptomyces sp. KY 40-1. ACS Chem. Biol. 12: 2529-2534.

11. Zhuang Y, Yang GY, Chen X, Liu Q, Zhang X, Deng Z, et al. 2017. Biosynthesis of plant-derived ginsenoside $\mathrm{Rh} 2$ in yeast via repurposing a key promiscuous microbial enzyme. Metab. Eng. 42: 25-32.

12. Xue C, Tian L, Xu M, Deng Z, Lin W. 2008. A new 24membered lactone and a new polyene $\delta$-lactone from the marine bacterium Bacillus marinus. J. Antibiot. 61: 668-674.

13. Qin W, Liu Y, Ren P, Zhang J, Li H, Tian L, et al. 2014. Uncovering a glycosyltransferase provides insights into the glycosylation step during macrolactin and bacillaene biosynthesis. Chembiochem 15: 2747-2753.

14. Liu Y, Qin W, Liu Q, Zhang J, Li H, Xu S, et al. 2016. Genome-wide identification and characterization of macrolide glycosyltransferases from a marine-derived Bacillus strain and their phylogenetic distribution. Environ. Microbiol. 18: 4770-4781.

15. Gustafson KR, Roman M, Fenical W. 1989. The macrolactins, a novel class of antiviral and cytotoxic macrolides from a deep-sea marine bacterium. J. Am. Chem. Soc. 111: 7519-7524.

16. Sun L, Chen D, Chen R, Xie K, Liu J, Yang L, et al. 2016. Exploring the aglycon promiscuity of a new glycosyltransferase from Pueraria lobata. Tetrahedron Lett. 57: 1518-1521. 